Article

\title{
Laser-Induced Graphene-Based Enzymatic Biosensor for Glucose Detection
}

\author{
Kalpana Settu *D, Pin-Tzu Chiu and Yu-Ming Huang
}

check for updates

Citation: Settu, K.; Chiu, P.-T.;

Huang, Y.-M. Laser-Induced

Graphene-Based Enzymatic Biosensor for Glucose Detection. Polymers 2021,

13, 2795. https://doi.org/10.3390/ polym 13162795

Academic Editors: José Miguel Ferri and Claudio Gerbaldi

Received: 5 July 2021

Accepted: 17 August 2021

Published: 20 August 2021

Publisher's Note: MDPI stays neutral with regard to jurisdictional claims in published maps and institutional affiliations.

Copyright: (c) 2021 by the authors. Licensee MDPI, Basel, Switzerland. This article is an open access article distributed under the terms and conditions of the Creative Commons Attribution (CC BY) license (https:// creativecommons.org/licenses/by/ $4.0 /)$.
Department of Electrical Engineering, National Taipei University, New Taipei City 23741, Taiwan; s410787003@gm.ntpu.edu.tw (P.-T.C.); idris.herondale@gmail.com (Y.-M.H.)

* Correspondence: kalpana@mail.ntpu.edu.tw; Tel.: +886-2867-4111-1 (ext. 68806)

\begin{abstract}
Laser-induced graphene (LIG) has recently been receiving increasing attention due to its simple fabrication and low cost. This study reports a flexible laser-induced graphene-based electrochemical biosensor fabricated on a polymer substrate by the laser direct engraving process. For this purpose, a $450 \mathrm{~nm}$ UV laser was employed to produce a laser-induced graphene electrode (LIGE) on a polyimide substrate. After the laser engraving of LIGE, the chitosan-glucose oxidase (GOx) composite was immobilized on the LIGE surface to develop the biosensor for glucose detection. It was observed that the developed LIGE biosensor exhibited good amperometric responses toward glucose detection over a wide linear range up to $8 \mathrm{mM}$. The GOx/chitosan-modified LIGE biosensor showed high sensitivity of $43.15 \mu \mathrm{AmM}^{-1} \mathrm{~cm}^{-2}$ with a detection limit of $0.431 \mathrm{mM}$. The interference studies performed with some possible interfering compounds such as ascorbic acid, uric acid, and urea exhibited no interference as there was no difference observed in the amperometric glucose detection. It was suggested that the LIGE-based biosensor proposed herein was easy to prepare and could be used for low-cost, rapid, and sensitive/selective glucose detection.
\end{abstract}

Keywords: biosensor; laser-induced graphene; polyimide; glucose; enzyme

\section{Introduction}

Numerous novel and cutting-edge technologies and materials are necessary to satisfy the new trends and requisites of analytical systems as the needs for environmental, biomedical, food and beverage analysis are progressing very quickly. The development of biosensors has evolved as one of the most promising research directions to overcome these challenges. Therefore, biosensor-based techniques have recently started being applied for the determination of different clinically, environmentally and biologically active materials [1-3]. In this regard, the design of biosensors in nanoscience/nanotechnology, environmental, medicine and food monitoring has been significantly increased during the past decade for their extensive applications. These advanced technologies have assisted the construction of highly sensitive, selective, customizable, and portable sensors for the determination of various clinically significant materials such as glucose, etc. [4]. The progress of such glucose biosensors has an inordinate significance in diagnosing and controlling diabetes mellitus, which is considered a worldwide public health problem. Diabetes mellitus would increase the risk of heart disease, kidney failure, blindness, postoperative and wound infections $[5,6]$.

Diabetes mellitus has increased worldwide over the past five decades. Diabetes is a medical condition in which patients experience glucose concentration diverging from the normal range of $80-120 \mathrm{mg} / \mathrm{dL}$ (4.4-6.6 mM) [7]. In 2019, the International Diabetes Federation (IDF) assessments indicated that approximately 463 million adults have diabetes, and it might rise to 700 million by 2045 [8]. Diabetic patients are required to perform glucose testing several times a day to maintain normal glucose levels. Hence, the rapid quantification of glucose concentration in bodily fluids is vital for diagnosing and treating 
diabetic patients. For this purpose, the design of an easy, rapid and low-cost technology for the determination of glucose is essential in clinical diagnosis $[9,10]$.

Glucose biosensors have significantly contributed to the detection of glucose levels in diabetic patients [11,12]. Studies have indicated that among various biosensors, glucose oxidase (GOx) enzyme-based electrochemical biosensors were considered to offer good selectivity and sensitivity for glucose detection $[13,14]$. Amperometry is the widely used electrochemical technique for glucose detection. Amperometric sensors could provide several advantages, such as ease of use, short analysis time, high sensitivity, and higher signal-to-noise ratio compared to other sensors [14-16]. The common idea applied for the development of amperometric biosensors is the efficiency of charge transfer, which can be better enhanced. Additionally, the biocompatibility issues of the sensors could be resolved by modifying electrodes with polymers such as chitosan or hydrogels [17]. In addition, various features of the electrodes could easily be altered by selecting the optimal chemical and electrochemical parameters during the effective electrode modifications $[18,19]$.

The amperometric glucose biosensor generally uses an enzyme glucose oxidase (GOx), which catalyzes glucose oxidation at the electrode and provides high selectivity in glucose detection. Most enzymatic amperometric biosensors are based on disposable screen-printed enzyme electrode strips [20-22]. However, the wastage of materials might occur during the screen-printing process, limiting the applications of screen-printed electrodes.

Graphene, a carbon-based nanomaterial, has gained substantial attention in many areas. In terms of electrochemical properties, graphene could provide high conductivity with a remarkable heterogeneous electron transfer rate [23,24]. In 2014, it was found that polymers such as polyimide (PI) could be directly converted into porous graphene using a $\mathrm{CO}_{2}$ laser machine with a $10.6 \mu \mathrm{m}$ wavelength [25]. In addition to infrared $\mathrm{CO}_{2}(10.6 \mu \mathrm{m})$ laser, visible laser [26-31] and ultraviolet laser [32] have also been successfully used to synthesize laser-induced graphene (LIG). The laser-irradiation of the PI film caused the photo-thermal generation of the graphene due to the local heating of the film. Upon heating the film, the carbon atoms bonded with oxygen $(C-O, C=O)$ and nitrogen $(C-N)$ atoms via $\mathrm{sp}^{3}$ and $\mathrm{sp}^{2}$ hybridization breakdown and rearranged to form several layers of $\mathrm{sp}^{2}$ hybridized carbon atoms of graphene $[25,33]$. The laser induction of graphene has been performed in ambient conditions without any material wastage. In addition, the shape/pattern of LIG could also be easily customized by computer design, which holds great promise toward developing glucose biosensors.

Recently, Pereira et al. demonstrated the electrochemical response of GOx adsorbed on a $\mathrm{CO}_{2}$ laser-scribed LIG [34]. The GOx enzyme adsorbed on LIG remained catalytically active even after running the cyclic voltammetry up to $+1.0 \mathrm{~V}$ for glucose detection. The LIG electrodes facilitated the direct electron transfer between the GOx and the electrode surface without mediators.

In this study, we fabricated a laser-induced graphene electrode (LIGE) by simple direct laser engraving with the UV laser on polyimide tape. The LIGE surface was immobilized with GOx/Chitosan composite for selective detection on glucose. Amperometric measurement was used to quantify the glucose concentration with the developed LIGE enzymatic biosensor. The novelty of the present work lies in the detection of glucose with enhanced sensitivity using a simple, low-cost LIGE-based biosensor.

\section{Materials and Methods}

\subsection{Chemicals and Instruments}

Glucose, uric acid, ascorbic acid, chitosan, and glucose oxidase (GOx, from Aspergillus niger, Type X-S, lyophilized powder, 118,000 units/g solid) were purchased from SigmaAldrich Corp. (St. Louis, MO, USA). A single-sided Kapton ${ }^{\circledR}$ polyimide tape with a film thickness of $\sim 30.4 \mu \mathrm{m}$ and a width of $50 \mathrm{~mm}$ was obtained from STAREK Scientific Co., Ltd. (Taipei, Taiwan). Photo/printing paper (HYA300, A4-120 $\mathrm{gm}^{-2}, 0.15 \mathrm{~mm}$ ) was purchased from a local book store. All the electrochemical measurements were conducted using a portable potentiostat (PalmSens 4, PalmSens, Houten, The Netherlands). Raman 
spectroscopic study was conducted using a micro-Raman spectrometer (JASCO NRS4100; Laser $532 \mathrm{~nm}$ ) with a spectral resolution of $2 \mathrm{~cm}^{-1}$. Data processing/plotting was performed using Origin 9.1 software (OriginLab Inc., Northampton, MA, USA).

\subsection{Fabrication of LIGE Sensor}

A 3-electrode system was designed using AutoCAD software with a $3 \mathrm{~mm}$ diameter of working electrode and laser-inscribed to graphene-based electrodes. Kapton ${ }^{\circledR}$ polyimide tape was pasted onto a paper substrate and cleaned with isopropanol and deionized water. Then, the designed pattern made in graphic software was inscribed on the surface of the Kapton tape using a laser engraving machine (HANLIN 7WLS, 7 W, $450 \mathrm{~nm}$ ) to form highly conductive graphene electrodes, as shown in Figure 1. The resistance of the graphenebased electrode was optimized by adjusting the laser power intensity ( $22 \%$ of the machine's maximum power), engraving depth (5\%), the distance between the laser head and the polyimide substrate $(\sim 13 \mathrm{~cm})$. The duration for fabricating a complete LIGE sensor was $2.8 \mathrm{~min}$.

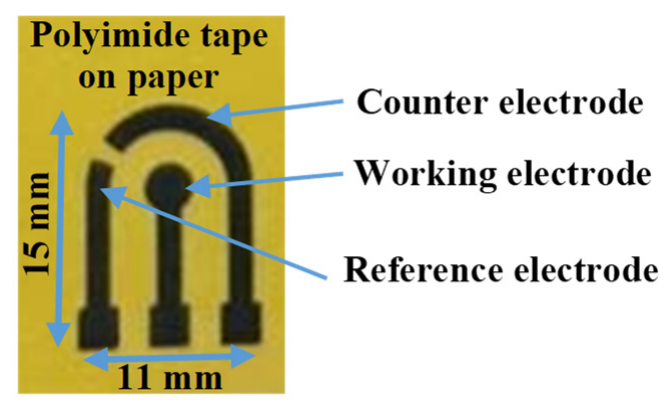

Figure 1. LIG 3-electrode system on polyimide tape fabricated by laser inscribing.

\subsection{Immobilization of GOx/Chitosan Composite on the LIGE}

The glucose biosensor was prepared by immobilizing the glucose oxidase and chitosan hydrogel homogeneous biocomposite on the LIGE surface. The resulting biocomposite could retain the enzyme bioactivity at considerably extreme conditions [35]. Five milligrams of GOx and three milligrams of chitosan were dissolved in $0.5 \mathrm{~mL}$ of deionized water and stirred for $5 \mathrm{~min}$ [36]. Subsequently, $5 \mu \mathrm{L}$ of the mixture was cast onto the surface of the LIGE working electrode. Then, the LIGE sensor was kept in a refrigerator at $4{ }^{\circ} \mathrm{C}$ for $24 \mathrm{~h}$.

\subsection{Electrochemical Measurements}

All the electrochemical measurements were carried out using PalmSens 4 potentiostat (PalmSens, Houten, The Netherlands) at room temperature. The electrochemical redox characteristics of the LIGE were measured by Cyclic voltammetry (CV) with different concentrations of potassium ferri (III)cyanide $\left(\mathrm{K}_{3}\left[\mathrm{Fe}(\mathrm{CN})_{6}\right]\right)$ in $50 \mathrm{mM}$ of phosphate-buffered solution (PBS). CV measurements were performed at a scan rate of $50 \mathrm{mV} / \mathrm{s}$ with a potential range from -0.8 to $+0.8 \mathrm{~V}$. Chronoamperometry (CA) experiments for glucose detection with LIGE were performed in $50 \mathrm{mM}$ PBS at the fixed applied voltage of $0.8 \mathrm{~V}$ for $60 \mathrm{~s}$. The detection principle of glucose is based on the electron transfer mechanism. GOx reacts with glucose in the presence of $\mathrm{O}_{2}$ and produces gluconolactone and $\mathrm{H}_{2} \mathrm{O}_{2}$. A change in electrical current occurs at the electrode surface during these reactions due to the electron transfer. Additionally, the resulting current response is proportional to the number of glucose molecules present in the sample.

\subsection{Optimization of Applied Potential and $\mathrm{pH}$}

CA measurements were used to determine the optimal applied potential and $\mathrm{pH}$ for glucose detection. The CA potential was optimized by varying the potential from $0.3 \mathrm{~V}$ to $1.3 \mathrm{~V} \mathrm{(5} \mathrm{mM} \mathrm{Glucose,} \mathrm{pH} 7$ ), and the resulting CA current was sampled at $60 \mathrm{~s}$. CA 
measurements were performed with a LIGE biosensor at $5 \mathrm{mM}$ glucose solution with the applied potential of $0.8 \mathrm{~V}$ by varying the $\mathrm{pH}$ of the phosphate-buffered solution from a $\mathrm{pH}$ of 5 to 9 , and the optimal $\mathrm{pH}$ was found.

\subsection{Interference Study}

The response of the LIGE biosensor for glucose detection was evaluated in the presence of potential interferences such as $0.1 \mathrm{mM}$ ascorbic acid, $0.1 \mathrm{mM}$ uric acid, and $3 \mathrm{mM}$ urea ( $\mathrm{pH} 7 ; 5 \mathrm{mM}$ glucose; $0.8 \mathrm{~V}$ ).

\section{Results and Discussion}

\subsection{Characterization of LIGE \\ 3.1.1. Raman Spectra}

In this study, a graphene three-electrode system for electrochemical sensing applications was developed by direct laser inscribing on polymer substrate (Polyimide). The prepared LIGE was characterized with Raman spectra, as shown in Figure 2. The Raman spectrum consists of $\mathrm{G}$ band at ca. $1592 \mathrm{~cm}^{-1}$ related to the $\mathrm{E}_{2 \mathrm{~g}}$ phonon of the $\mathrm{sp}^{2}$ carbon atoms, and $\mathrm{D}$ band at ca. $1340 \mathrm{~cm}^{-1}$ corresponds to the disordered grain boundaries [37,38]. Two other bands were observed at 2697 and $2900 \mathrm{~cm}^{-1}$. The band at ca. $2700 \mathrm{~cm}^{-1}$ is known as the 2D band, an indicator of the number of graphene layers. A sharp peak will appear at ca. $2700 \mathrm{~cm}^{-1}$ for monolayer graphene. Here, the broadened band was observed, which would be attributed to the prepared graphene containing many layers with some defects. The band that appeared at $2900 \mathrm{~cm}^{-1}$ is called an S3 band, which is a second-order peak derived from the D-G peak combination. The band intensity ratio of S3-2D is proportional to the reduction in defects [38]. This Raman spectra result indicated that the obtained black material on polyimide substrate was carbon-based graphene.

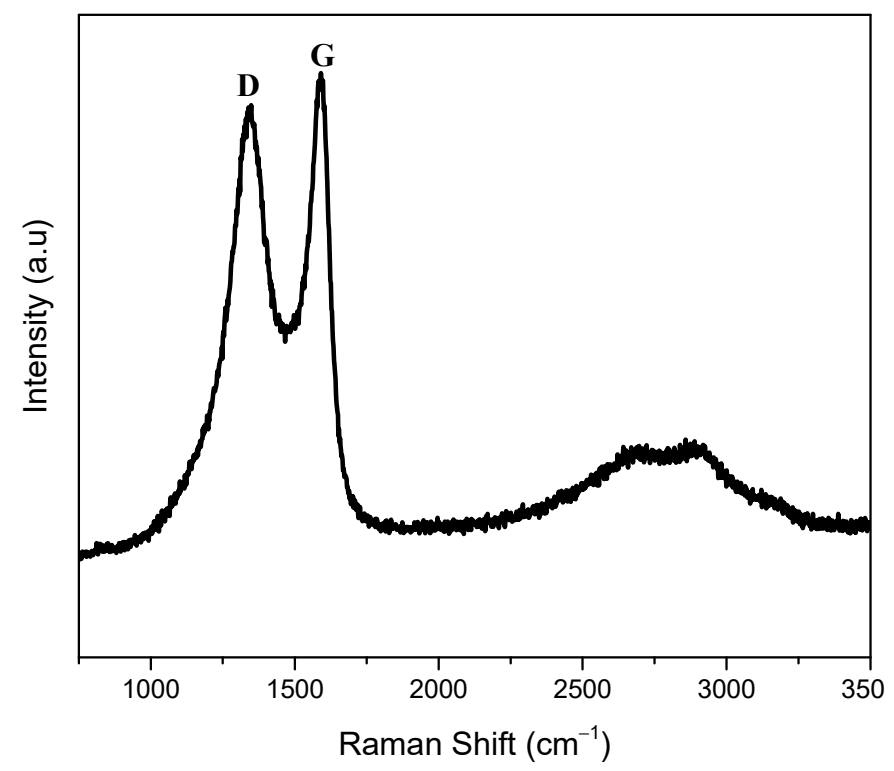

Figure 2. Raman spectra of LIGE.

\subsubsection{Electrochemical Characterization}

Before developing the glucose biosensor with LIGE, validating the LIGE sensor towards electrochemical sensing was necessary. The ferri/ferrocyanide $\left(\mathrm{Fe}(\mathrm{CN})_{6}{ }^{3-/ 4-}\right)$ redox couple is one of the most widely used electron mediators for electrochemical reactions [39]. The performance of an electrochemical sensor towards an electron mediator was considered most relevant to general biochemical sensing applications. Thus, the electrochemical efficacy of the LIGE sensor was evaluated using cyclic voltammetry responses in different concentrations of ferricyanide redox mediator $\left(\mathrm{K}_{3}\left[\mathrm{Fe}(\mathrm{CN})_{6}\right]\right)$, as shown in Figure 3a. As seen from Figure 3a, the oxidation peaks' current increased from 35.495 to $65.043 \mu \mathrm{A}$ 
when the ferricyanide concentration ranged from 0.5 to $2.5 \mathrm{mM}$. The oxidation peak current showed an excellent linear relationship with different ferricyanide concentrations, as shown in Figure 3b. The linear regression equation was $y=14.54 x+28.69\left(R^{2}=0.998\right)$, where $y$ and $x$ are the height of oxidation peak current $(\mu \mathrm{A})$ and $\left(\mathrm{K}_{3}\left[\mathrm{Fe}(\mathrm{CN})_{6}\right]\right)$ concentration $(\mathrm{mM})$, respectively. The fabricated LIGE provided a favorable response for varying ferricyanide concentrations, indicating excellent electrocatalytic properties. Moreover, the reproducibility of all CV responses was within 5\% RSD (relative standard deviation) $(n=4)$. These results demonstrated the remarkable electrocatalytic response of the fabricated LIGE sensor.

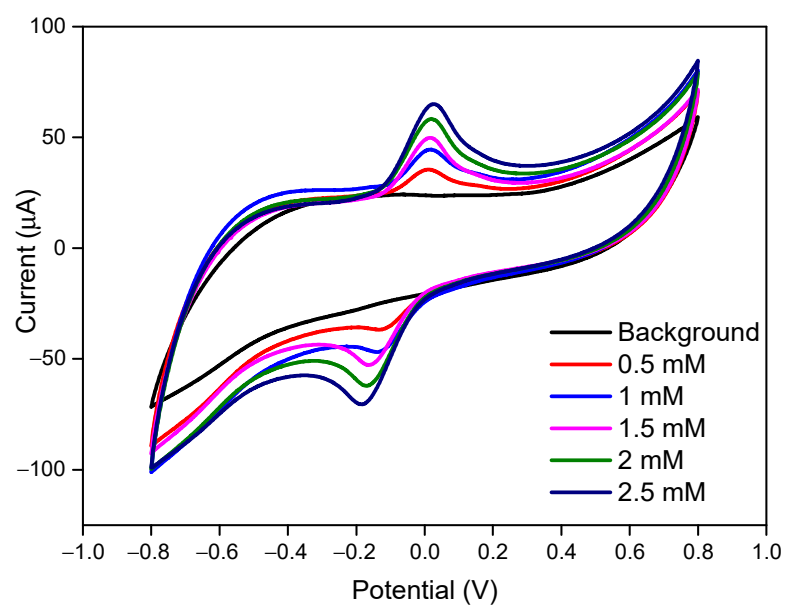

(a)

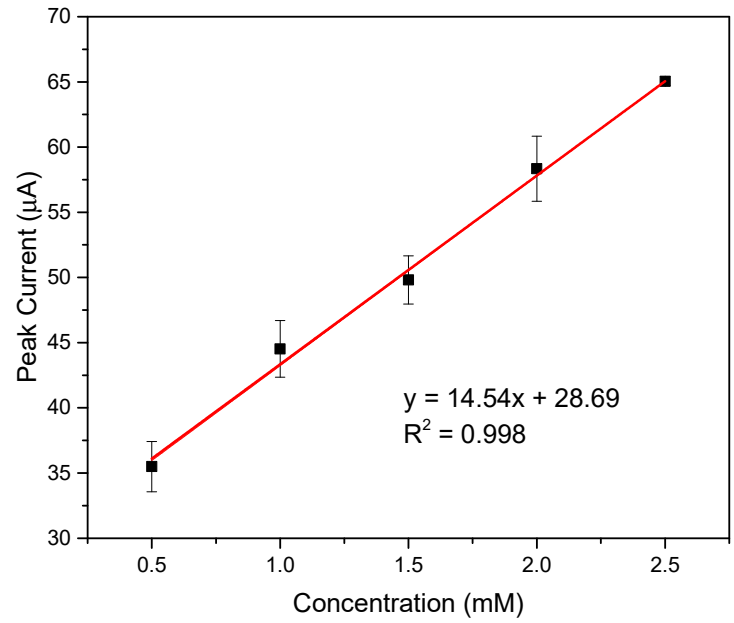

(b)

Figure 3. (a) CV responses of ferricyanide solutions with varying concentrations; and (b) oxidation current peaks vs. concentration. Scan rate was $50 \mathrm{mV} \mathrm{s}^{-1}$.

\subsection{Characterization of GOx/Chitosan Immobilized LIGE}

Cyclic voltammetry measurement was performed to confirm the LIGE immobilization with GOx/Chitosan. Figure 4 shows the cyclic voltammograms of potassium ferricyanide at bare LIGE and GOx/chitosan composite-modified LIGE. It can be seen that after the immobilization of GOx/chitosan composite onto the LIGE surface, the peak current decreased to 24.325 from $58.336 \mu \mathrm{A}$ of the bare LIGE. The electron transfer kinetics of $[\mathrm{Fe}(\mathrm{CN}) 6]^{4-} /[\mathrm{Fe}(\mathrm{CN}) 6]^{3-}$ is significantly hindered after the LIGE surface was modified with GOx/chitosan. This result confirmed that the GOx/chitosan was successfully immobilized on the LIGE surface.

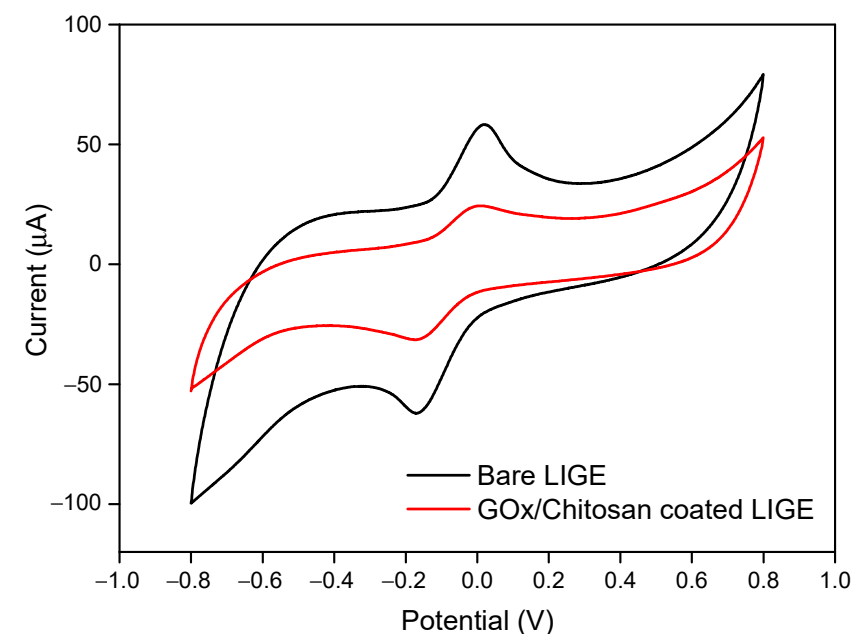

Figure 4. Cyclic voltammograms on bare LIGE and GOx/chitosan-modified LIGE in the presence of $2 \mathrm{mM}$ potassium ferricyanide. 


\subsection{Amperometric Detection of Glucose by the Proposed LIGE}

The chronoamperometry technique was employed to detect glucose using GOx/ Chitosan coated LIGE sensor at a constant oxidation potential of $+0.8 \mathrm{~V}$. Figure 5 a depicts the chronoamperometric responses of the LIGE biosensor with glucose concentrations ranging from 0 to $10 \mathrm{mM}$. The current response increased with increasing glucose concentrations. The steady-state current response at $60 \mathrm{~s}$ was chosen for the detection of glucose concentration. The amperometric current response of the LIGE biosensor exhibited a linear relationship with the glucose concentrations ranging from 0 to $8 \mathrm{mM}$, and the current began to level off at a glucose concentration higher than $8 \mathrm{mM}$ as shown in Figure $5 \mathrm{~b}$. The linear regression equation was $y=3.05 x+8.54$, with a coefficient of determination $R^{2}=0.97$ and a sensitivity of $43.15 \mu \mathrm{A} \mathrm{mM} \mathrm{M}^{-1} \mathrm{~cm}^{-2}$. The limit of detection was calculated according to the $3 s_{a} / b$ criterion, where $b$ was the slope of the calibration curve, and $s_{a}$ was the estimated standard deviation of the y-intercepts of the regression line [3]. The detection limit calculated was $0.431 \mathrm{mM}$. As seen from Figure $5 \mathrm{~b}$, the linear part of the calibration curve includes the normal glucose levels (4.4 to $6.6 \mathrm{mM}$ ) in the human blood. Thus, this study could offer a simple approach for the clinical glucose measurement with a disposable LIGE-based biosensor. The performance of the proposed biosensor was compared with other reported glucose biosensors, as shown in Table 1. The developed LIGE-based enzymatic glucose biosensor exhibited good analytical characteristics towards glucose detection such as good linearity and high sensitivity. Moreover, the fabrication and detection procedures of the proposed LIGE-based biosensor were also simple, rapid, and cost-effective.

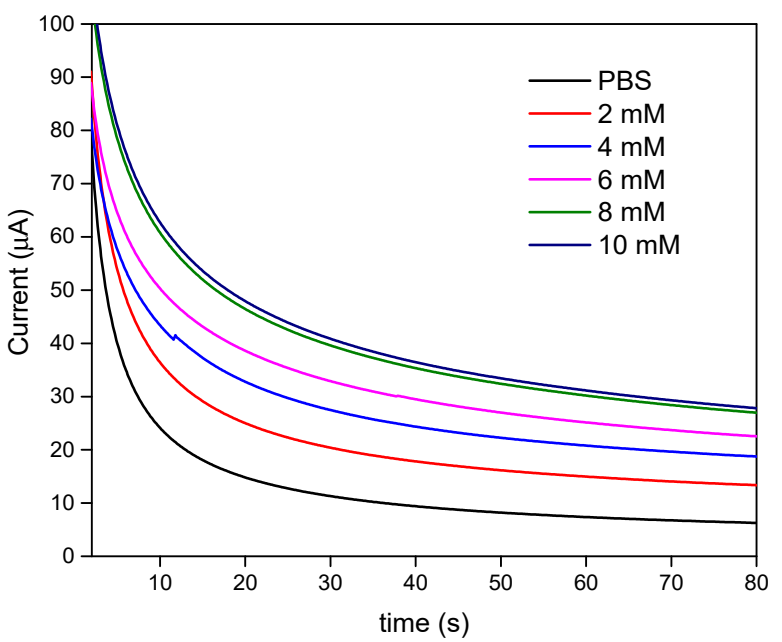

(a)

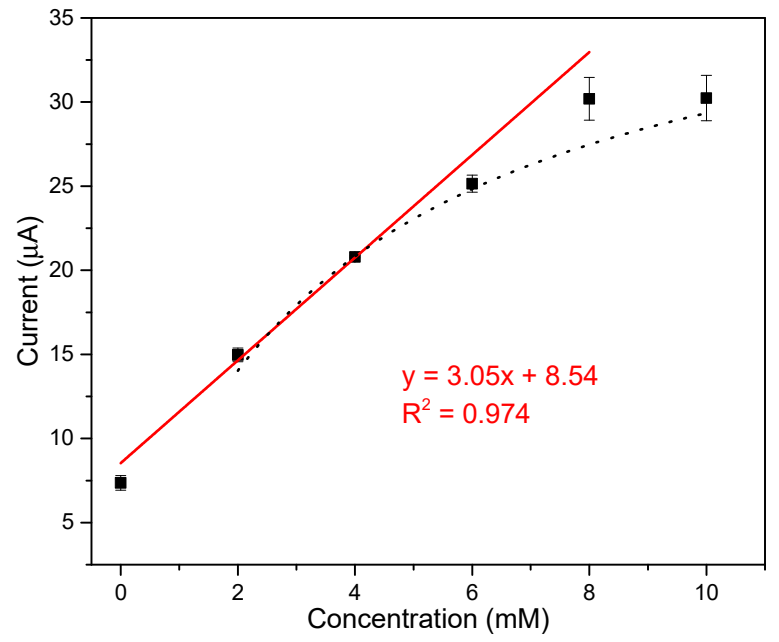

(b)

Figure 5. (a) Chronoamperometry response with different concentrations of glucose; (b) the relationship between the glucose concentration and the chronoamperometric current response at $60 \mathrm{~s}$.

Table 1. Comparison of the analytical performance of glucose biosensors.

\begin{tabular}{|c|c|c|c|c|}
\hline Glucose Biosensor $^{a}$ & Sensitivity $\left(\mu \mathrm{A} \mathrm{mM^{-1 } \mathrm { cm } ^ { - 2 } )}\right.$ & Linear Range (mM) & LOD $(\mu \mathrm{M})$ & Reference \\
\hline GOx/Chitosan-modified LIGE & 43.15 & $0-8$ & 431 & This work \\
\hline $\mathrm{GC} / \mathrm{MWCNT} / \mathrm{Fe}_{3} \mathrm{O}_{4} / \mathrm{PDA}-\mathrm{GOx}$ & 5.04 & $2-20$ & 2.25 & [40] \\
\hline LSG/PBSE/PtNPs/GOx & 12.64 & $0.005-3.2$ & 2.57 & [41] \\
\hline $\mathrm{MoS}_{2} /$ Chitosan/GOx-Gelatin/PGE & $0.8\left(\mu \mathrm{A} \mathrm{mM} M^{-1}\right)$ & $0.01-0.8$ & 3.18 & [42] \\
\hline $\mathrm{CPE} / \mathrm{GO} x-\mathrm{SiO}_{2} / \mathrm{Lig}$ & 0.78 & $0.5-9$ & 145 & [19] \\
\hline $\mathrm{Au}-\mathrm{Cys}-\mathrm{GA}-\mathrm{Gox}$ & 2.65 & $1.5-7$ & 940 & [43] \\
\hline $\mathrm{PPy} / \mathrm{GOD} / \mathrm{SPCE}$ & 0.21 & $0-5$ & - & [44] \\
\hline
\end{tabular}

${ }^{a}$ GC-glassy carbon electrode; MWCNT—multi-walled carbon nanotubes; $\mathrm{Fe}_{3} \mathrm{O}_{4} / \mathrm{PDA}$-magnetite/polydopamine; LSG-laser-scribed graphene; PBSE — pyrenebutanoic acid-succinimide ester; PtNPs—platinum nanoparticles; $\mathrm{MoS}_{2}$ —-molybdenum disulfide; PGE — pencil graphite electrode; $\mathrm{CPE}$ — carbon paste electrode; $\mathrm{SiO}_{2}$ / Lig—silica/lignin; Cys—cysteine; GA—glutaraldehyde; $\mathrm{PPy}$-polypyrrole; SPCE— screen-printed carbon electrodes; GOD/GOx-Glucose oxidase. 


\subsection{Michaelis-Menten Kinetics}

The maximum response current $\left(I_{\max }\right)$ and the apparent Michaelis-Menten constant $\left(\mathrm{K}_{\mathrm{m}}^{\mathrm{app}}\right)$ were used to analyze the relationship between chronoamperometric signals and enzymatic reaction. As shown in Figure 5b, when glucose concentration exceeds $6 \mathrm{mM}$, a response plateau was observed with the characteristic of Michaelis-Menten kinetic mechanism. From the calibration plot (Figure $5 \mathrm{~b}$ dotted line), the current response showed hyperbolic dependence on glucose concentration and was in good agreement with MichaelisMenten kinetics [45]. The kinetic parameters, the maximum current generated during the enzymatic reaction $\left(I_{\max }\right)$ and the apparent Michaelis constant $\left(\mathrm{K}_{\mathrm{m}}^{\mathrm{app}}\right)$ are the corresponding $a$ and $b$ parameters of hyperbolic function $y=a x /(b+x)$ [46]. The apparent MichaelisMenten constant $\left(\mathrm{K}_{\mathrm{m}}^{\mathrm{app}}\right)$ is an indication of enzymatic mimics-substrate kinetics. From the hyperbolic calibration plot (Figure $5 \mathrm{~b}$ dotted line), the $I_{\max }$ and Michaelis constant $\mathrm{K}_{\mathrm{m}}^{\mathrm{app}}$ were $40.34 \mu \mathrm{A}$ and $3.75 \mathrm{mM}$, respectively. The value of $\mathrm{K}_{\mathrm{m}}^{\mathrm{app}}$ is consistent with the reported value $\left(\mathrm{K}_{\mathrm{m}}^{\mathrm{app}}=3.84 \mathrm{mM}\right)$ for other GOx immobilized on the chitosan complex over triangular silver nanoprisms/platinum biosensor [47].

\subsection{Optimization of Applied Potential and Buffer $p H$}

Chronoamperometry measurements were used to determine the optimal applied potential and $\mathrm{pH}$ for glucose detection with the developed enzymatic LIGE biosensor. Figure 6a shows the chronoamperometric response of the LIGE biosensor at $60 \mathrm{~s}$ with different applied potential values ranging from 0.3 to $1.3 \mathrm{~V}$. The results showed that the current increased with increasing applied potential from 0.3 to $0.8 \mathrm{~V}$ and currents tended to level off when the potential increased beyond $0.8 \mathrm{~V}$. Thus, $0.8 \mathrm{~V}$ was selected as the optimized potential for amperometric glucose detection. Figure $6 \mathrm{~b}$ illustrates the chronoamperometry current response of the biosensor as a function of the $\mathrm{pH}$ of $\mathrm{PBS}$ containing $2 \mathrm{mM}$ glucose. The current responses at $\mathrm{pH} 5, \mathrm{pH} 6$, and $\mathrm{pH} 7$ were almost similar. Considering the $\mathrm{pH}$ of a physiological buffer, $\mathrm{pH} 7$ was chosen for the glucose detection experiments.

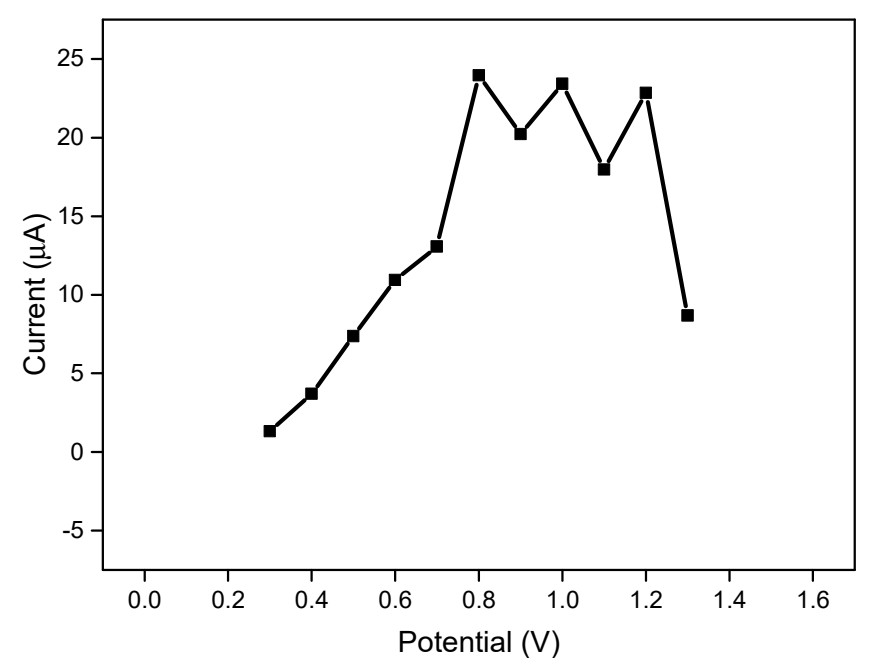

(a)

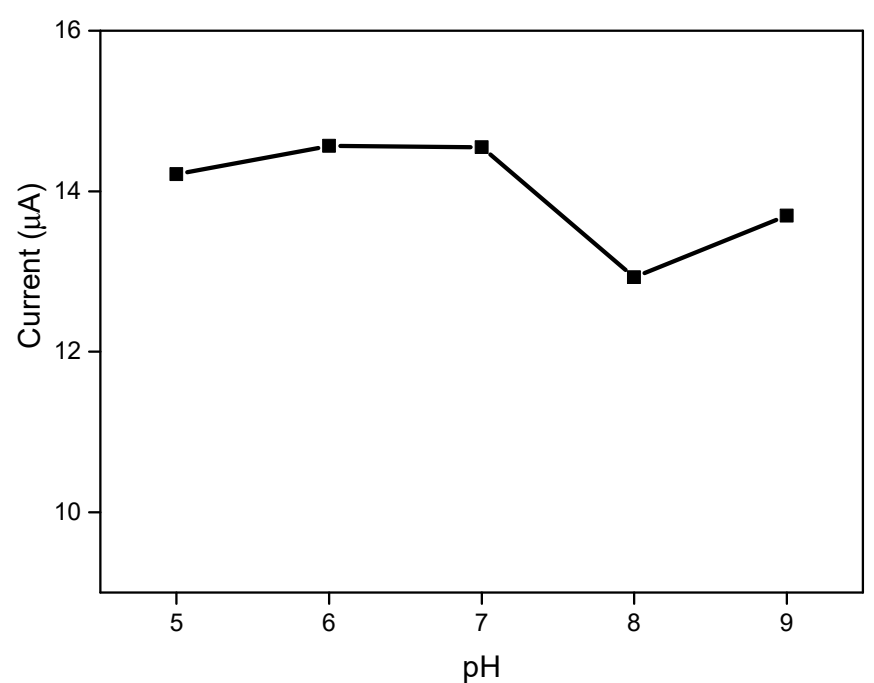

(b)

Figure 6. (a) Chronoamperometry response at $60 \mathrm{~s}$ in different applied potential with $5 \mathrm{mM}$ glucose; and (b) Chronoamperometry response at $60 \mathrm{~s}$ in different buffer $\mathrm{pH}$ with $2 \mathrm{mM}$ glucose.

\subsection{Interference Study}

The developed LIGE-based enzymatic biosensor was evaluated with possible interferences by comparing the chronoamperometric responses before and after adding some interferents such as ascorbic acid $(0.1 \mathrm{mM})$, uric acid $(0.1 \mathrm{mM})$, and urea $(3 \mathrm{mM})$ in $5 \mathrm{mM}$ glucose. As shown in Figure 7, the chronoamperometric current responses for glucose with- 
out and with interferents showed practically no interference. The LIGE was modified with GOx, which is the standard enzyme for biosensors and it has relatively higher selectivity for glucose [48]. Hence, the LIGE biosensor was suggested to possess good selectivity due to the specificity of the GOx enzyme.

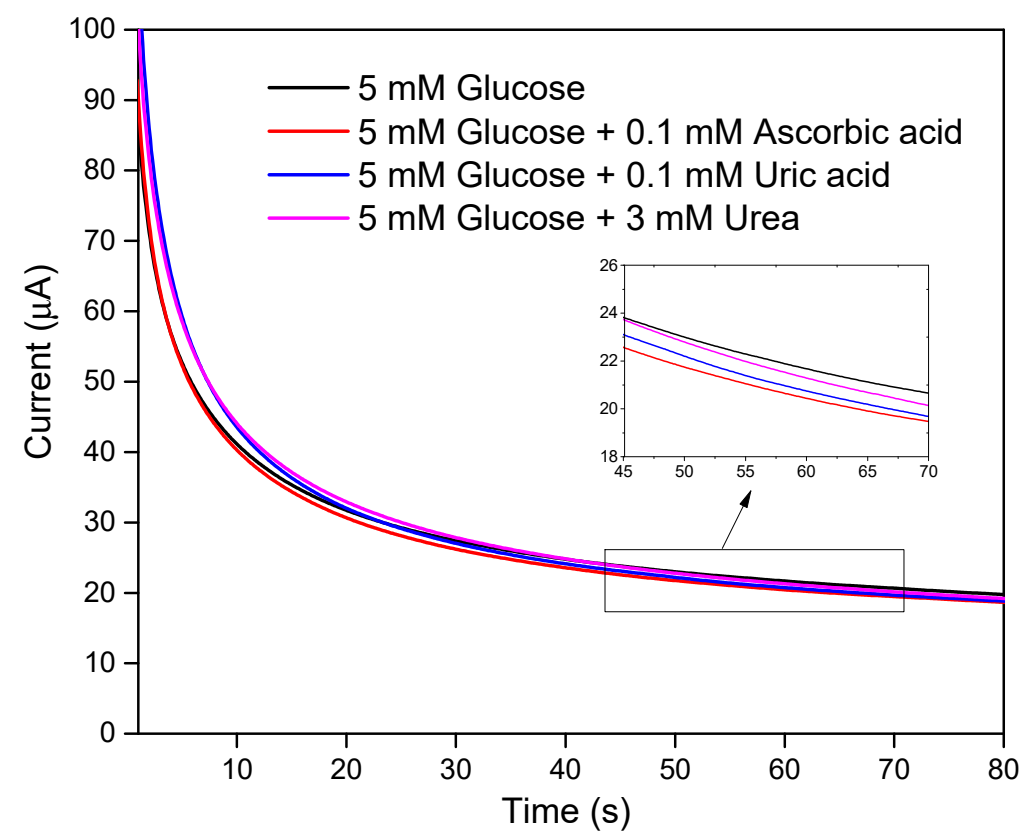

Figure 7. Chronoamperograms of $5 \mathrm{mM}$ glucose with/without interferences. The inset shows the zoomed part of the result from 45 to $70 \mathrm{~s}$.

\subsection{Stability and Reproducibility of Biosensor}

The stability of the developed GOx/chitosan-modified LIGE biosensor was evaluated by measuring the amperometric current response in the presence of $5 \mathrm{mM}$ glucose over 25 days stored at $4{ }^{\circ} \mathrm{C}$ in a refrigerator. The biosensor exhibited $\sim 90 \%$ stability for 10 days, and the response remained approximately $72-85 \%$ after 10 days. The reproducibility of the developed biosensor was assessed from the current response of different biosensors prepared independently. In this work, all the measurements were taken from at least three independent sensors $(n \geq 3)$, and the reproducible signals were obtained with the RSD less than $6 \%$.

\section{Conclusions}

We developed a simple laser-induced graphene-based enzymatic biosensor for glucose detection. The proposed detection strategy could offer an easy and low-cost route to mass-produce sensitive biosensing electrodes. The chronoamperometric measurements successfully detected the glucose over a linear range from 0 to $8 \mathrm{mM}$ with a detection limit of $0.431 \mathrm{mM}$. The biosensor response was not affected by interfering compounds (ascorbic acid, uric acid and urea) and demonstrated the high specificity and selectivity of this LIGE biosensor in glucose detection. The proposed LIGE biosensor holds excellent promise in point-of-care diagnosis. Our future study aims to validate the biosensor response in human blood samples for real-life applications.

Author Contributions: K.S.: conceptualization, supervision, validation, writing-review and editing; P.-T.C.: methodology, validation, data curation, writing_-original draft; Y.-M.H.: validation, data curation. All authors have read and agreed to the published version of the manuscript.

Funding: This research was supported under Grants MOST 110-2222-E-305-001 and MOST 107-2221E-305-012-MY3 by the Ministry of Science and Technology, Taiwan, and Grant 109-NTPU_ORDA-F008 by National Taipei University, Taiwan. 
Institutional Review Board Statement: Not applicable.

Informed Consent Statement: Not applicable.

Conflicts of Interest: The authors declare no conflict of interest.

\section{References}

1. Ramanavicius, S.; Ramanavicius, A. Charge Transfer and Biocompatibility Aspects in Conducting Polymer-Based Enzymatic Biosensors and Biofuel Cells. Nanomaterials 2021, 11, 371. [CrossRef] [PubMed]

2. Ramanavicius, S.; Ramanavicius, A. Conducting Polymers in the Design of Biosensors and Biofuel Cells. Polymers 2021, 13, 49. [CrossRef]

3. Ridhuan, N.S.; Razak, K.A.; Lockman, Z. Fabrication and Characterization of Glucose Biosensors by Using Hydrothermally Grown ZnO Nanorods. Sci. Rep. 2018, 8, 13722. [CrossRef] [PubMed]

4. German, N.; Ramanaviciene, A.; Ramanavicius, A. Dispersed Conducting Polymer Nanocomposites with Glucose Oxidase and Gold Nanoparticles for the Design of Enzymatic Glucose Biosensors. Polymers 2021, 13, 2173. [CrossRef]

5. Batool, R.; Rhouati, A.; Nawaz, M.H.; Hayat, A.; Marty, J.L. A review of the construction of nano-hybrids for electro-chemical biosensing of glucose. Biosensors 2019, 9, 46. [CrossRef]

6. Labib, M.; Sargent, E.H.; Kelley, S.O. Electrochemical Methods for the Analysis of Clinically Relevant Biomolecules. Chem. Rev. 2016, 116, 9001-9090. [CrossRef] [PubMed]

7. Blunt, B.A.; Barrett-Connor, E.; Wingard, D.L. Evaluation of Fasting Plasma Glucose as Screening Test for NIDDM in Older Adults: Rancho Bernardo Study. Diabetes Care 1991, 14, 989-993. [CrossRef]

8. IDF DIABETES ATLAS, 9th ed.; International Diabetes Federation, 2019; pp. 1-176. Available online: https://diabetesatlas.org/ en/resources / (accessed on 1 July 2021).

9. German, N.; Ramanaviciene, A.; Ramanavicius, A. Formation and Electrochemical Evaluation of Polyaniline and Polypyrrole Nanocomposites Based on Glucose Oxidase and Gold Nanostructures. Polymers 2020, 12, 3026. [CrossRef]

10. German, N.; Ramanaviciene, A.; Ramanavicius, A. Formation of polyaniline and polypyrrole nanocomposites with em-bedded glucose oxidase and gold nanoparticles. Polymers 2019, 11, 377. [CrossRef]

11. Gopalan, A.; Muthuchamy, N.; Lee, K. A novel bismuth oxychloride-graphene hybrid nanosheets based non-enzymatic photoelectrochemical glucose sensing platform for high performances. Biosens. Bioelectron. 2017, 89, 352-360. [CrossRef]

12. Sridara, T.; Upan, J.; Saianand, G.; Tuantranont, A.; Karuwan, C.; Jakmunee, J. Non-Enzymatic Amperometric Glucose Sensor Based on Carbon Nanodots and Copper Oxide Nanocomposites Electrode. Sensors 2020, 20, 808. [CrossRef]

13. Liu, S.; Ju, H. Reagentless glucose biosensor based on direct electron transfer of glucose oxidase immobilized on colloidal gold modified carbon paste electrode. Biosens. Bioelectron. 2003, 19, 177-183. [CrossRef]

14. Malitesta, C.; Palmisano, F.; Torsi, L.; Zambonin, P.G. Glucose fast-response amperometric sensor based on glucose oxidase immobilized in an electropolymerized poly(o-phenylenediamine) film. Anal. Chem. 1990, 62, 2735-2740. [CrossRef]

15. Gorton, L.; Bremle, G.; Csöregi, E.; Jönsson-Pettersson, G.; Persson, B. Amperometric glucose sensors based on immobilized glucose-oxidizing enzymes and chemically modified electrodes. Anal. Chim. Acta 1991, 249, 43-54. [CrossRef]

16. Koudelka, M.; Gernet, S.; De Rooij, N. Planar amperometric enzyme-based glucose microelectrode. Sens. Actuators 1989, 18, 157-165. [CrossRef]

17. Tajik, S.; Beitollahi, H.; Nejad, F.G.; Dourandish, Z.; Khalilzadeh, M.A.; Jang, H.W.; Venditti, R.A.; Varma, R.S.; Shokouhimehr, M. Recent Developments in Polymer Nanocomposite-Based Electrochemical Sensors for Detecting Environmental Pollutants. Ind. Eng. Chem. Res. 2021, 60, 1112-1136. [CrossRef]

18. Andriukonis, E.; Celiesiute-Germaniene, R.; Ramanavicius, S.; Viter, R.; Ramanavicius, A. From microorganism-based amperometric biosensors towards microbial fuel cells. Sensors 2021, 21, 2442. [CrossRef]

19. Jędrzak, A.; Rębiś, T.; Klapiszewski, Ł.; Zdarta, J.; Milczarek, G.; Jesionowski, T. Carbon paste electrode based on functional GOx/silica-lignin system to prepare an amperometric glucose biosensor. Sens. Actuators B Chem. 2018, 256, 176-185. [CrossRef]

20. Crouch, E.; Cowell, D.C.; Hoskins, S.; Pittson, R.W.; Hart, J.P. Amperometric, screen-printed, glucose biosensor for analysis of human plasma samples using a biocomposite water-based carbon ink incorporating glucose oxidase. Anal. Biochem. 2005, 347, 17-23. [CrossRef]

21. Gao, Q.; Guo, Y.; Zhang, W.; Qi, H.; Zhang, C. An amperometric glucose biosensor based on layer-by-layer GOx-SWCNT conjugate/redox polymer multilayer on a screen-printed carbon electrode. Sens. Actuators B Chem. 2011, 153, 219-225. [CrossRef]

22. Guan, W.-J.; Li, Y.; Chen, Y.-Q.; Zhang, X.-B.; Hu, G.-Q. Glucose biosensor based on multi-wall carbon nanotubes and screen printed carbon electrodes. Biosens. Bioelectron. 2005, 21, 508-512. [CrossRef]

23. Altuntas, D.B.; Tepeli, Y.; Anik, U. Graphene-metallic nanocomposites as modifiers in electrochemical glucose biosensor transducers. 2D Mater. 2016, 3, 034001. [CrossRef]

24. Pumera, M. Graphene in biosensing. Mater. Today 2011, 14, 308-315. [CrossRef]

25. Lin, J.; Peng, Z.; Liu, Y.; Ruiz-Zepeda, F.; Ye, R.; Samuel, E.L.G.; Yacaman, M.J.; Yakobson, B.I.; Tour, J.M. Laser-induced porous graphene films from commercial polymers. Nat. Commun. 2014, 5, 5714. [CrossRef]

26. Zhang, Z.; Song, M.; Hao, J.; Wu, K.; Li, C.; Hu, C. Visible light laser-induced graphene from phenolic resin: A new approach for directly writing graphene-based electrochemical devices on various substrates. Carbon 2018, 127, 287-296. [CrossRef] 
27. Romero, F.J.; Salinas-Castillo, A.; Rivadeneyra, A.; Albrecht, A.; Godoy, A.; Morales, D.P.; Rodriguez, N. In-Depth Study of Laser Diode Ablation of Kapton Polyimide for Flexible Conductive Substrates. Nanomaterials 2018, 8, 517. [CrossRef]

28. Stanford, M.G.; Zhang, C.; Fowlkes, J.D.; Hoffman, A.; Ivanov, I.N.; Rack, P.D.; Tour, J.M. High-Resolution Laser-Induced Graphene. Flexible Electronics beyond the Visible Limit. ACS Appl. Mater. Interfaces 2020, 12, 10902-10907. [CrossRef]

29. Tao, L.-Q.; Tian, H.; Liu, Y.; Ju, Z.-Y.; Pang, Y.; Chen, Y.-Q.; Wang, D.-Y.; Tian, X.-G.; Yan, J.-C.; Deng, N.-Q.; et al. An intelligent artificial throat with sound-sensing ability based on laser induced graphene. Nat. Commun. 2017, 8, 14579. [CrossRef]

30. Bobinger, M.R.; Romero, F.J.; Salinas-Castillo, A.; Becherer, M.; Lugli, P.; Morales, D.P.; Rodríguez, N.; Rivadeneyra, A. Flexible and robust laser-induced graphene heaters photothermally scribed on bare polyimide substrates. Carbon 2019, 144, 116-126. [CrossRef]

31. Cai, J.; Lv, C.; Watanabe, A. Cost-effective fabrication of high-performance flexible all-solid-state carbon mi-cro-supercapacitors by blue-violet laser direct writing and further surface treatment. J. Mater. Chem. A 2016, 4, 1671-1679. [CrossRef]

32. Carvalho, A.F.; Fernandes, A.J.S.; Leitao, C.; Deuermeier, J.; Marques, A.; Martins, R.; Fortunato, E.; Costa, F.M. Laser-Induced Graphene Strain Sensors Produced by Ultraviolet Irradiation of Polyimide. Adv. Funct. Mater. 2018, 28, 1805271. [CrossRef]

33. Tehrani, F.; Bavarian, B. Facile and scalable disposable sensor based on laser engraved graphene for electrochemical detection of glucose. Sci. Rep. 2016, 6, 1-10. [CrossRef] [PubMed]

34. Pereira, S.; Santos, N.; Carvalho, A.; Fernandes, A.; Costa, F. Electrochemical Response of Glucose Oxidase Adsorbed on Laser-Induced Graphene. Nanomaterials 2021, 11, 1893. [CrossRef]

35. Luo, X.-L.; Xu, J.-J.; Du, Y.; Chen, H.-Y. A glucose biosensor based on chitosan-glucose oxidase-gold nanoparticles bio-composite formed by one-step electrodeposition. Anal. Biochem. 2004, 334, 284-289. [CrossRef] [PubMed]

36. Yoon, H.; Nah, J.; Kim, H.; Ko, S.; Sharifuzzaman, M.; Barman, S.C.; Xuan, X.; Kim, J.; Park, J.Y. A chemically modified laserinduced porous graphene based flexible and ultrasensitive electrochemical biosensor for sweat glucose detection. Sens. Actuators B Chem. 2020, 311, 127866. [CrossRef]

37. Si, Y.; Samulski, E.T. Synthesis of water soluble graphene. Nano Lett. 2008, 8, 1679-1682. [CrossRef]

38. Johra, F.T.; Lee, J.-W.; Jung, W.-G. Facile and safe graphene preparation on solution based platform. J. Ind. Eng. Chem. 2014, 20, 2883-2887. [CrossRef]

39. Sriprachuabwong, C.; Karuwan, C.; Wisitsorrat, A.; Phokharatkul, D.; Lomas, T.; Sritongkham, P.; Tuantranont, A. Inkjet-printed graphene-PEDOT:PSS modified screen printed carbon electrode for biochemical sensing. J. Mater. Chem. 2012, 22, 5478-5485. [CrossRef]

40. Kuznowicz, M.; Jędrzak, A.; Rębiś, T.; Jesionowski, T. Biomimetic magnetite/polydopamine/ $\beta$-cyclodextrins nanocomposite for long-term glucose measurements. Biochem. Eng. J. 2021, 174, 108127. [CrossRef]

41. Hossain, F.; Slaughter, G. Flexible electrochemical uric acid and glucose biosensor. Bioelectrochemistry 2021, 141, 107870. [CrossRef]

42. Altuntaş, D.B.; Kuralay, F. MoS2/Chitosan/GOx-Gelatin modified graphite surface: Preparation, characterization and its use for glucose determination. Mater. Sci. Eng. B 2021, 270, 115215. [CrossRef]

43. Lović, J.; Stevanović, S.; Nikolić, N.D.; Petrović, S.; Vuković, D.; Prlainović, N.; Mijin, D.; Ivić, M.A. Glucose Sensing Using Glucose Oxidase-Glutaraldehyde-Cysteine Modified Gold Electrode. Int. J. Electrochem. Sci. 2017, 12, 5806-5817. [CrossRef]

44. Weng, B.; Morrin, A.; Shepherd, R.; Crowley, K.; Killard, A.J.; Innis, P.C.; Wallace, G.G. Wholly printed polypyrrole na-noparticlebased biosensors on flexible substrate. J. Mater. Chem. B 2014, 2, 793-799. [CrossRef] [PubMed]

45. Gao, Z.; Lin, Y.; He, Y.; Tang, D. Enzyme-free amperometric glucose sensor using a glassy carbon electrode modified with poly(vinyl butyral) incorporating a hybrid nanostructure composed of molybdenum disulfide and copper sulfide. Microchim. Acta 2017, 184, 807-814. [CrossRef]

46. Anusha, J.; Raj, C.J.; Cho, B.-B.; Fleming, A.T.; Yu, K.-H.; Kim, B.C. Amperometric glucose biosensor based on glucose oxidase immobilized over chitosan nanoparticles from gladius of Uroteuthis duvauceli. Sens. Actuators B Chem. 2015, 215, 536-543. [CrossRef]

47. Shi, W.; Ma, Z. Amperometric glucose biosensor based on a triangular silver nanoprisms/chitosan composite film as immobilization matrix. Biosens. Bioelectron. 2010, 26, 1098-1103. [CrossRef]

48. Bankar, S.; Bule, M.V.; Singhal, R.; Ananthanarayan, L. Glucose oxidase-An overview. Biotechnol. Adv. 2009, $27,489-501$. [CrossRef] 